\title{
TRABAJO, SUFRIMIENTO E IDEOLOGÍA EN LA SOCIEDAD NEOLIBERAL
}

\author{
Labor, Suffering and Ideology in the Neoliberal Society
}

\author{
Aarón Vázquez Peñas \\ Universidad Complutense de Madrid \\ aaronvaz@ucm.es
}

\section{Resumen:}

Apoyándose en las investigaciones del psicopatólogo del trabajo Christophe Dejours, el artículo trata de analizar la proliferación de determinados relatos ideológicos característicos de la sociedad neoliberal, en relación con las estructuras de organización del trabajo y el registro de ciertos fenómenos sistemáticos de sufrimiento laboral que le son propios.

\section{Palabras clave:}

Ideología, sufrimiento laboral, C. Dejours, sociedad neoliberal

\begin{abstract}
:
With the support of psicopathologist of work Christophe Dejours, the paper attemps try to analyze the proliferation of some ideological narratives characteristic of neoliberal society, related to the organization of work structures and the recording of certain systematic phenomena of labor suffering that are inherent to it.
\end{abstract}

Keywords:

Ideology, Labor Suffering, C. Dejours, Neoliberal Society

Recibido: 20/02/2019

Aceptado: 30/05/2019 


\section{INTRODUCCIÓN}

El presente trabajo se inscribe en un horizonte de investigación más amplio que responde a un interés fundamental por alcanzar una comprensión crítica del funcionamiento y la naturaleza específica de nuestras sociedades actuales, con especial atención a la repercusión de las modificaciones en el modelo productivo correlativas a la progresiva implementación de la racionalidad gubernamental neoliberal a partir de la crisis de los setenta. En concreto aquí se pretende, en primer lugar, coadyuvar a combatir la invisibilización de cierto sufrimiento laboral generalizado y sistemático, el cual, por lo demás, habida cuenta de la innegable centralidad social y cultural del empleo en el mundo contemporáneo y en la época moderna en general, incide de manera determinante en el problema más amplio del sufrimiento social' y en el análisis social como tal (Dejours, 2009:11-12) ${ }^{2}$. El segundo objetivo esencial, en estrecha relación con lo anterior, no es otro que proporcionar algunas claves explicativas de ciertos mecanismos o condiciones de asimilación, propagación y refuerzo de determinados relatos ideológicos en nuestras sociedades, subrayando además el papel decisivo de este fenómeno en el mantenimiento y perpetuación del statu quo. Así, trataremos de aportar algunas respuestas a la cuestión de por qué y de qué manera ciertas ideologías tienden a ser hoy masivamente interiorizadas pasando a formar parte de una mentalidad social hegemónica o en camino de serlo.

En el marco de este estudio, el vocablo trabajo no referirá, desde luego, a la capacidad humana general de realizar un esfuerzo deliberado y continuado para lograr alguna meta, así como tampoco a toda actividad productiva en cuanto tal (que podríamos remontar a la poiesis aristotélica), ni a ciertas actividades de voluntariado, ni al denominado trabajo reproductivo o trabajo de cuidados, sino sólo y específicamente a la actividad remunerada en el mercado, de manera que expresiones como «trabajo», «empleo» o «actividad laboral» se utilizarán indistintamente. Tal vez no esté de más, en todo caso, introducir tres importantes notas en este punto. Primeramente, valga indicar que con esta acotación semántica no se pretende en absoluto sugerir que este sentido restringido del trabajo en tanto que mera actividad remunerada sea el único uso viable del concepto en cualquier contexto posible ${ }^{3}$. Establecida esta advertencia, habría que llamar asimismo la atención sobre el hecho de que las relaciones entre trabajo y sufrimiento no tienen por qué ser exclusivas del ámbito específico del trabajo asalariado, de suerte que, aunque ese no sea el cometido del presente artículo, sería también posible detectar

\footnotetext{
1 Vid. "El sufrimiento social. Entrevista a Emmanuel Renault", recurso online disponible en http://espaienblanc.net/?autores=espai-en-blanc (última visita: 17-01-2019).

2 Nos referimos a la centralidad del trabajo en sentido descriptivo, no necesariamente normativo. Sobre el alcance de esta distinción, vid. Noguera (2002:148).

${ }^{3}$ Vid. Antonio Noguera, «El problema de la definición del trabajo» (recurso online disponible en:https://gsadi.uab.cat/images/pdfs/noguera/El\%20problema\%20de\%20la\%20definici\%C3\% B3n\%20del\%20trabajo.pdf). Cf. Dejours (2009a:18).
} 
fenómenos de sufrimiento humano socialmente relevante asociados al desempeño de determinados trabajos no asalariados y/o no remunerados ${ }^{4}$. Por descontado, tampoco habríamos de suponer de antemano que el sufrimiento social sistémico a propósito del empleo se agota en la consideración del sufrimiento en el trabajo ${ }^{5}$, si bien en este caso se tratará de poner el foco precisamente en el sufrimiento de quienes trabajan y no tanto en los padecimientos asociados, por ejemplo, a las situaciones de desempleo. Por de pronto se tratará de plantear que el sufrimiento, las relaciones de dominación y la injusticia social afectan también a quienes poseen un puesto de trabajo, no solamente a los desempleados, pobres y marginados (sin que, por otra parte, con ello queramos dar a entender, habida cuenta de la vigente importancia de la figura del «working poor», que en la presente circunstancia política, social y laboral el hecho de poseer un empleo excluya por definición la posibilidad de estas dos últimas condiciones ${ }^{6}$ ).

Sirva ello, a su vez, para poner sobre el tapete la idea de que la actividad laboral no es buena per se, siendo así que a ese respecto todo depende de la calidad del empleo en cuestión ${ }^{7}$. El trabajo remunerado, ciertamente, no es necesaria ni unilateralmente positivo para los individuos que lo desempeñan (más allá de su condición de medio para obtener ingresos). Desde luego, no siempre es conveniente para su salud física y mental, ni para su autoestima, ni para su capacidad de controlar su propia biografía, ni para preservar su integridad moral. Así pues, junto a los objetivos específicos más arriba anunciados, en las próximas líneas nos gustaría además contribuir de un modo más general a poner en tela de juicio algunas de las principales connotaciones habituales del fenómeno del empleo en cuanto tal.

El término ideología ${ }^{8}$, por su parte, no referirá simplemente a una determinada representación del mundo o conjunto de creencias involucradas en determinadas

\footnotetext{
${ }^{4}$ En realidad, el trabajo asalariado sería un subconjunto del trabajo remunerado en general. El caso de los autónomos, por ejemplo, muestra que no todo trabajo con remuneración en el mercado es propiamente asalariado (Raventós, 1999:61).
}

${ }^{5}$ En efecto, es posible hablar de repercusiones negativas sobre la calidad de vida y de sufrimiento en razón del trabajo más allá de lo que sucede en los lugares de trabajo propiamente dichos. El sociólogo galés David Frayne, por ejemplo, ha abordado convenientemente este asunto al señalar en qué sentido puede hablarse incluso de un «trabajo fuera del trabajo», Ilamando especialmente la atención sobre las repercusiones personales del imperativo de «trabajar» incesantemente en la propia «empleabilidad» (Frayne, 2017: 85-94).

${ }^{6}$ Vid. Dejours, 2009b:10, 35-43, donde se ponen en uso los conceptos de «subproletariado» y de «subempleo» a propósito de la situación laboral de buena parte de los habitantes masculinos de los suburbios en los años setenta y ochenta en Francia. Cf. Dejours, 2009c:19, 24-25.

${ }^{7}$ Vid. Supra., nota 25.

${ }^{8}$ En las siguientes líneas tenemos muy en cuenta la excelente síntesis de las diversas acepciones del término y la problematización del concepto ofrecidas por Terry Eagleton en 
dinámicas práctico-materiales propias de ciertos grupos humanos, sino que se empleará también y de manera fundamental en el sentido peyorativo y restrictivo de falsa conciencia, enmascaramiento o distorsión de la realidad que favorece intereses ilegítimos por cuanto fomenta la naturalización de cierto orden social y laboral dominante que se presupone injusto. Dos observaciones esenciales acerca de nuestro uso de la expresión «falsa conciencia». En primer lugar, indicaremos que - como tendremos ocasión de mostrar posteriormente- ésta no tiene por qué ser producto de un engaño voluntario9. En segundo lugar, aclarar que con esa nota en la definición no nos referimos a que todas y cada una de las creencias o aseveraciones particulares que puedan ser tachadas de ideológicas, o que puedan ser consideradas como parte de cierto constructo o entramado ideológico, sean estricta y necesariamente falsas como tales (aunque, desde luego, bien puedan serlo), sino que, resultando centrales por lo que hace a la reproducción de un sistema social dado, más bien serían susceptibles de ser así calificadas en tanto que - por decirlo de algún modo- consciente o inconscientemente inducirían o tenderían a suscitar de facto una representación general de la realidad en gran medida sesgada, en tanto que -en nuestra particular coyuntura- vendría a adolecer de un grado de parcialidad tal que la tornaría a todas luces falsa. Y, por supuesto, con «parcialidad» no nos referimos aquí a una suerte de ausencia de neutralidad (esto es, a una toma de partido que pretende sin embargo pasar por una simple descripción presuntamente «objetiva» de los hechos), sino a un tipo de concepción de la realidad social y laboral que, para empezar y sobre todo, ofusca, oculta, invisibiliza y/o trivializa determinados fenómenos sistémicos y experiencias humanas que habrían de ser considerados relevantes (en nuestro caso, fenómenos decisivos de sufrimiento en el trabajo y la injusticia social en cuanto tal).

\section{EL PAPEL DE LA IDEOLOGÍA}

Las consideraciones que a continuación que se verterán están en buena medida inspiradas por diversas investigaciones de Christophe Dejours, especialmente por un estudio publicado en francés en 1999, titulado en castellano La banalización de la injusticia social, y, en una edición posterior de la que nosotros nos hemos valido, Trabajo y sufrimiento: cuando la injusticia se hace banal. Pese a haber transcurrido ya dos décadas desde su primera edición, estimamos que el planteamiento general del libro no ha perdido ni un ápice de actualidad. Su punto de partida histórico nos retrotrae hasta el año 1980, fecha que, como es sabido, viene a coincidir con el inicio de la llamada ofensiva neoliberal a raíz de la crisis del keynesianismo ${ }^{10}$, y que

los dos primeros capítulos de Ideología. Una introducción (1997: 15-91). Nuestro uso del concepto aquí incorpora no solamente una dimensión sociológica, sino asimismo epistemológica y normativa. No obstante, de manera análoga a lo que observábamos sobre el concepto de trabajo, con ello no pretendemos sugerir que ese sea el único empleo posible y correcto del término en cualquier circunstancia. Cf. Dejours, 2009b: 154, $42-43$ (nota).

${ }^{9}$ Vid. supra., nota 13.

${ }^{10}$ Vid. Harvey: 2007; Laval/ Dardot, 2013:189-246. 
- frente a una izquierda europea cuyo programa no contemplaba, ya desde la década de los setenta, el problema del sufrimiento laboral como tal (Dejours, 2009a:53-57; 2009b:27; López Álvarez:2016) - marcaría en el mundo occidental un cambio muy significativo en lo tocante a las reacciones sociales ante el sufrimiento y las injusticias sistémicas: una notable disminución de la indignación, la cólera y la movilización colectivas. El leitmotiv del libro es, por tanto, la pretensión de contribuir a esclarecer el fenómeno de la indiferencia generalizada y la creciente tolerancia social hacia la injusticia en el régimen neoliberal. A lo largo de la obra asistimos a una exploración de los «resortes subjetivos» de ese consentimiento y participación masivos, los cuales juegan un rol decisivo en la medida en que, una vez más, sin cierta actitud de complicidad por parte del grueso de la población que presta su concurso al funcionamiento de la «máquina», el sistema no se sostendría.

Comentaba Terry Eagleton que no debería sobredimensionarse el peso de la ideología para el mantenimiento del statu quo, ya que hay métodos, factores materiales y, en fin, elementos más prosaicos que explican en mucha mayor medida la integración de los sujetos en un sistema social, político y económico que, aun pudiendo ser contemplado de forma crítica, no tiene menos poder o capacidad -material- de sometimiento (el crítico literario y cultural británico ilustraba esta idea mediante el ejemplo de $M$. Thatcher, que, pese a su famosa frase, en realidad no habría conseguido "conquistar el alma» de la mayor parte de la ciudadanía inglesa al no haber logrado que gran parte del pueblo inglés llegase a identificarse con sus valores, lo cual, sin embargo, no impidió que gobernara durante toda una década). A ese respecto hay que apuntar que precisamente uno de los aspectos a nuestro juicio más destacables del trabajo de Dejours es su voluntad de explicar la sociogénesis y la proliferación de ciertos relatos ideológicos en íntima relación con determinadas condiciones materiales objetivas. Y ello hasta el punto de que la tolerancia de los sujetos a determinadas coyunturas laborales únicamente sería posible gracias a determinados procedimientos subjetivos racionalizadores - en el sentido psicoanalítico de la expresión-y de carácter ideológico, presentando de ese modo a estos últimos como fuertemente condicionados por las condiciones y exigencias laborales en cuestión. Como vemos, la dimensión ideológica aparece necesariamente involucrada en la realidad material (como, por lo demás, Eagleton acaba reconociendo posteriormente en su texto) y viceversa, operando ambas como elementos en cierto modo inextricables en cuanto codependientes, si bien perfectamente disociables en el pensamiento y manteniendo al mismo tiempo entre sí una relación de condicionamiento, no así de estricta e irremediable determinación (Dejours, 2009a:27, 164).

Si tomamos ahora en consideración que la susodicha transformación económicosocial acontecida a partir de los ochenta coincide con el comienzo de profundas mutaciones en el campo de la organización del trabajo (Dejours, 2009c:89; Sennet, 2005), estamos en condiciones de recoger una de las tesis vertebradoras del texto de Dejours, que además dotará de sentido a todo cuanto expondremos en lo que resta del presente escrito: el mencionado consentimiento masivo estaría estrechamente relacionado con el sufrimiento de los trabajadores asociado a las múltiples exigencias a las que se ven sometidos bajo ese nuevo modelo de organización del 
trabajo y de gestión empresarial' ${ }^{1}$. Sufrimiento que, por tanto, lejos de ser contraproducente para el funcionamiento del sistema, paradójicamente tiende a producir de facto adhesión y tolerancia hacia el mismo ${ }^{12}$. Tiende, diríamos, a contribuir a perpetuar sus injusticias en la medida en que suscita estrategias psicológicas de defensa que permiten sortear la desestructuración psíquica tornando aceptable lo que de otra manera sería intolerable ${ }^{13}$.

La ideología aparecerá pues, ciertamente, como algo imprescindible, pero a modo de reacción o respuesta frente a unas condiciones materiales dadas. Aquí vuelve a apreciarse con claridad el fondo, diríamos, sociológico y materialista de la metodología adoptada. A la luz de los resultados e investigaciones clínicas en materia de psicodinámica y psicopatología del trabajo ${ }^{14}$, las conductas y los procesos

\footnotetext{
${ }^{11}$ Importa tener presente la nítida distinción entre organización del trabajo y condiciones de trabajo asumida por nuestro autor. Si en el segundo caso estaríamos haciendo referencia a "todos los ambientes físicos (...), químicos (...) y biológicos (...), las condiciones de higiene, de seguridad, y las características métricas y espaciales del puesto de trabajo", en el primero se trata de "la división del trabajo, el contenido de la tarea (derivado de ella), el sistema jerárquico, las formas de mando, las relaciones de poder, las cuestiones de responsabilidad, etc." (Dejours, 2019a:31). Cf. Dejours, 2010:28-29. Según el esquema propuesto, las condiciones de trabajo estarían fundamentalmente vinculadas al asunto de la salud de los cuerpos, mientras que la problemática de la salud mental y el sufrimiento psíquico guardaría relación más bien con la esfera de la organización del trabajo.
}

12 Se trataría, en el fondo, de cierta actualización del problema clásico de la servidumbre voluntaria (Dejours, 2009a:14). Vid. Dejours, 2009b:101-122.

${ }^{13}$ Repárese en que, según esto, lo que resulta funcional al sistema no es el sufrimiento en sí, sino - para ser más exactos- los referidos mecanismos de defensa contra ese sufrimiento ocasionado por la organización del trabajo (Dejours, 2009b:108). En este sentido aclarábamos anteriormente que el fenómeno de la falsa conciencia no ha de ser necesariamente fruto de alguna suerte de engaño intencionado, ya que, en efecto, puede constituir también un autoengaño. Ahora bien, conviene reparar en que "si obviamente no va en interés de un grupo oprimido autoengañarse sobre su situación, sí va en su interés en otro sentido, pues este autoengaño puede volver más tolerables sus condiciones" (Eagleton, 1997:80, cursiva nuestra). Así las cosas, puede decirse que la ideología, cuando adopta la forma de estrategia defensiva, juega un papel hasta cierto punto paradójico, además de obligarnos a matizar notablemente su dimensión estrictamente despreciable en cuanto presunta pura y simple interiorización servil e ignorante de la dominación social y de los discursos dominantes (vid. Dejours, 2009a:51,187). Por otro lado, aunque son recursos subjetivos y bien pueden conformar un eje fundamental de la identidad personal de los individuos, los relatos ideológicos sin embargo no son privados ni fruto del capricho de quien los hace suyos: la ideología aparece a menudo como "un cajón de sastre de refranes y citas impersonales y sin sujeto" (Eagleton, 1997:42). Vid. Dejours, 2009a:167.

14 Inicialmente concebida como una disciplina encargada de diagnosticar afecciones psicopatológicas causadas por el trabajo, en los últimos treinta años la llamada psicopatología del trabajo ha experimentado una evolución que ha conducido a un cambio de denominación, sustituyéndose el rótulo en cuestión por la expresión más general «análisis 
subjetivos individuales que contemplaremos y analizaremos a continuación de la mano de nuestro autor, lejos de poseer un carácter espontáneo o «natural», se revelarán como el producto de un amplio proceso de construcción nunca exenta de cierto grado de fragilidad y encaminada a volver soportables determinadas situaciones y requerimientos laborales.

\section{SUFRIMIENTO EN EL TRABAJO Y «ESTRECHAMIENTO DE LA CONCIENCIA INTERSUBJETIVA»}

Una de las fuentes por excelencia del sufrimiento laboral que nos ocupa es la experiencia del mied $o^{15}$. Para empezar, $\mathrm{y}$, sobre todo, ante la constante amenaza de despido. A menudo, por ejemplo, muchos trabajadores toleran la progresiva precarización de su puesto de trabajo, dada la posibilidad de recurrir al empleo precario para reemplazarlos o de que sean despedidos a la menor infracción. El miedo genera sumisión, tiende a debilitar los lazos de solidaridad entre los dominados, a favorecer la aceptación de situaciones que en otro tiempo no hubieran sido toleradas y a producir indiferencia ante el sufrimiento de los otros (tanto del resto de los trabajadores como de los desempleados y marginados sociales).

Además del recién referido, existen toda una serie de padecimientos relacionados con la experiencia del temor a la incompetencia, la sobrecarga de trabajo, la duración y distribución de la jornada, los impedimentos para realizar correctamente las tareas asignadas en un clima social en el trabajo con frecuencia harto deteriorado, la falta de reconocimiento por el esfuerzo realizado, etc., la mayor parte de los cuales estarían íntimamente conectados con la negación sistemática (por parte de la dirección y del "discurso oficial») de "lo real» en el trabajo ${ }^{16}$, hecho que

psicodinámico de la situación del trabajo», que, por su parte, vendría a caracterizarse como un análisis clínico y teórico "de la relación subjetiva de los hombres y las mujeres con sus situaciones de trabajo". Sobre las razones de esta ampliación del marco de estudio y el consecuente cambio de nombre de la disciplina, vid. «De la psicodinámica a la psicopatología del trabajo», añadido de 1993 al ensayo Travail usure mental: essai de psychopathologie du travail, publicado por vez primera en 1980 (Dejours, 2009b:161-202). Vid. Dejours 2009a:31-32 [nota], 49-50.

${ }^{15}$ Para una diferenciación explícita entre este fenómeno y la experiencia de la angustia en sentido psicoanalítico, vid. Dejours, $2009 \mathrm{~b}: 71$.

${ }^{16}$ Se trata de un concepto clave en el discurso de Dejours sobre el que volveremos y que, por de pronto, viene a impugnar la dicotomía tradicional entre trabajo de concepción y trabajo de ejecución, por cuanto designa una brecha insalvable entre la tarea prescrita y la actividad real (exigencias efectivas o "experiencia vivida» del trabajo), presente hasta en las tareas más fraccionadas y consideradas de ejecución estricta. Por más que pueda estar rigurosamente organizado y diseñado por expertos (ingenieros de métodos, diseñadores o personal de gestión de recursos humanos), el trabajo nunca se reduce a las órdenes o indicaciones formuladas por la jerarquía. No es posible dominarlo y preverlo todo de antemano. Siempre existen, por diversas razones, fracasos, dificultades, anomalías e imprevistos que asaltan necesariamente sobre la marcha. Enfrentarse a lo cual requiere lo que se denomina «celo en el trabajo», es decir, una sabiduría pragmática o conocimiento operativo que constituye el 
conduce a atribuir los fracasos en el trabajo ordinario exclusivamente al Ilamado «factor humano» (culpabilizando al trabajador), sin tomar en cuenta las inevitables limitaciones de la organización prescrita.

Mas lo que en este momento interesa destacar es que, al no poder expresarlo públicamente, entre otras cosas porque se supone que quien trabaja es un privilegiado en relación con quienes se encuentran parados, el sujeto trabajador de alguna manera se repliega sobre sí «blindándose» en su propio sufrimiento, lo que conlleva una cierta insensibilización frente al padecimiento ajeno o el desarrollo de una cierta tolerancia hacia el mismo. Como vemos, es la relación del sujeto con su propio sufrimiento la que propicia su indiferencia ante el de los demás. Y una de las más frecuentes reacciones psíquicas defensivas desencadenadas por la negación del propio sufrimiento, la creciente precarización del empleo, la disminución de la demanda de fuerza de trabajo y el consecuente miedo a la exclusión es la adopción de los lemas individualistas del "cada uno a lo suyo» y del "sálvese quien pueda", inseparables de lo que Dejours Ilamará el mecanismo psicológico individual de las «anteojeras voluntarias» y del fenómeno del «estrechamiento de la conciencia intersubjetiva».

En ambos casos se trata de cerrar los ojos ante la realidad del sufrimiento ajeno erigiendo ciertos «obstáculos» contra su plena toma de conciencia. A través de la estrategia de defensa en cuestión esa negación "queda disimulada bajo la máscara de la ignorancia requerida por la aplicación, la concentración y el celo en la tarea" (Dejours, 2009a:161). Nos hallamos ante un fenómeno psicológico designado mediante la expresión «normopatía por sector», en gran medida favorecida además por la división social del trabajo. Hablamos de una insensibilidad total respecto a todo cuanto no resulta inmediatamente presente, próximo o adyacente a la situación concreta de los sujetos. De una absoluta carencia de empatía, compasión, compromiso, responsabilidad, conciencia moral y capacidad de juzgar, derivados

contenido de la actividad, irreductible a la tarea prescita como tal y que no pocas veces requiere inventiva, improvisación, la puesta en marcha de diversos recursos de la propia personalidad y de una inteligencia corporal que en ocasiones va por delante de la conciencia de los propios agentes, así como de notables esfuerzos de cooperación que trascienden la mera coordinación. Formas de cooperación -es importante decirlo- que precisan de elementos ajenos a la técnica, como el acuerdo colectivo y la confianza recíproca, en las que por tanto entra en juego la libertad de los sujetos y que, además, no se pueden concretar a priori, por lo que tampoco pueden prescribirse propiamente. En definitiva, según esto todo trabajo implica, en mayor o menor medida, el ejercicio de la inteligencia (tanto individual como colectiva) y, más en general, de una «movilización subjetiva» por parte del asalariado (lo cual, por otra parte, significa que, sin perjuicio de los contundentes procesos de automatización en curso, el trabajo humano o trabajo viviente será siempre en alguna medida necesario). Las referencias a esta noción son múltiples: Dejours, 2009a:113-115, 42, 50, 69-74, 76-80, 83, 86, 136; Dejours, 2009b:14, 109, 119, 169-178; Dejours, 2009c:18, 20-22, 44, 45, 74, 102; Dejours, 2010:42. 
fundamentalmente de "una falta de imaginación en cuanto a la condición subjetiva" (Dejours, 2009a:154) de los otros, y, con ello, de una completa ausencia de la noción misma de universalidad moral. De ahí la posibilidad de hacer referencia a este recurso masivo también en términos de conciencia moral restringida o de "estrechamiento concéntrico de la conciencia, de la responsabilidad y del compromiso moral" (Dejours, 2009a:161).

Como no podía ser de otra manera, tienen más probabilidades de recurrir a esta estrategia quienes no son capataces ni mandos directivos, o bien aquellos obreros de base que por el momento no se ven afectados por la amenaza de despido inminente, así como también, en general, quienes únicamente tienen noticia de la injusticia laboral por los medios de comunicación o por el testimonio de terceros: "Ios que no trabajan, los jubilados que no vivieron las actuales condiciones de trabajo, los jóvenes que aún no se vieron enfrentados al trabajo in situ, las amas de casa, etc." (Dejours, 2009a:163).

\section{LA SUMISIÓN SISTEMÁTICA A LA MENTIRA Y «LA ESTRATEGIA DE DISTORSIÓN} COMUNICATIVA»

Otro elemento del análisis de Dejours al que ya nos referimos de pasada en el epígrafe anterior y al que a nuestro juicio es preciso atender de manera explícita, es la notable disparidad o discordancia entre la descripción oficial del trabajo (proporcionada por los departamentos de calidad, de métodos y de gestión de recursos humanos) y la descripción de la experiencia realmente vivida del trabajo reconstruida a partir de los relatos de sus protagonistas. Y el asunto no es tanto que la primera sea siempre estricta y completamente falsa, sino que más bien es necesariamente parcial, por cuanto tiene un importante límite constitutivo: “(...) el trabajo [rea\ no presenta de ninguna manera el carácter normalizado y controlado que supone la descripción oficial" (Dejours, 2009a:70) ${ }^{17}$.

En relación con esto último nuestro autor observa que, aun conociendo la situación real, los mandos intermedios siempre mienten cuando se dirigen a investigadores, clientes o visitantes. Y no sólo omiten lo que saben, sino que incluso suelen mostrar cierto aire triunfalista respecto al porvenir de la empresa. «Optimismo» que contrasta, sin embargo, con su clara conciencia de las grandes dificultades existentes para mantener los objetivos en un contexto de falta crónica de personal para sacar el trabajo adelante.

Lo anterior sólo sería posible, en primer lugar, debido a que los mandos intermedios no suelen compartir con sus homólogos los impedimentos y contrariedades a las que se enfrentan a diario en su trabajo, lo que hace que ello no pueda ser objeto de reflexión colectiva. Y no lo hacen, una vez más, por miedo a que la exposición de sus propias dificultades les conduzca a ser vistos por los colegas como unos incompetentes, y de que —en última instancia- ello les aboque eventualmente a formar parte del paquete de excluidos. Además, al mismo tiempo,

17 Vid. infra, nota 16 
basándose en su propia experiencia del miedo, conocen de primera mano que la amenaza de despido es un excelente método para que sus subordinados aumenten el ritmo de trabajo hasta niveles desorbitados, si se lo compara con lo que sucedía al respecto algunas décadas atrás. Este hecho determina, por otra parte, que la competencia entre quienes buscan trabajo y los trabajadores con contrato relativamente estable se acentúe cada vez más, en una circunstancia en la que la demanda de empleo se ve rebasada con creces por la oferta. Así entonces, si bien las recompensas y gratificaciones por el trabajo bien hecho no están del todo ausentes, los resultados se obtienen esencialmente gracias a la «gestión por amenaza».

Hay un segundo aspecto que explicaría no sólo la mencionada omisión de información, sino también la visible fe de los mandos intermedios en el buen funcionamiento del sistema y su actitud como colaboradores celosos de la organización y su gestión. Dado el silencio sistemático al respecto al que recién nos referíamos, las dificultades que surgen en la tarea laboral rara vez llegan a ser conocidas por los directivos. $Y$ hay más: la versión oficial sobre el trabajo y su organización describe siempre la producción a partir de los resultados obtenidos y no de las actividades que dieron lugar a los mismos (las cuales, sin embargo, forman parte de la verdad del funcionamiento de la empresa en sentido estricto ${ }^{18}$ ), poniendo además de relieve exclusivamente aquellos de signo positivo. Ciertamente, ese discurso (originado en las más altas esferas de la compañía) está pensado a modo de propaganda dirigida al exterior de la empresa, con vistas a salvaguardar su buena imagen social. Pero $-y$ esto es lo más relevante aquí- actualmente estaría asimismo diseñado para servir a determinados objetivos internos vinculados a la noción de "cultura de empresa», en clave de una suerte de propaganda comercial destinada a los mismos asalariados (Dejours, 2009a:88-90). Insistamos en que el relativo éxito del uso de esta propaganda se ve favorecido por la fragmentación de la empresa contemporánea y por la susodicha negación constante y generalizada de $l o$ rea/en el trabajo, que hacen posible que finalmente esa tergiversación de la realidad pueda prevalecer, en el interior de la compañía, sobre otros puntos de vista harto divergentes...

El sistema de producción y control de las prácticas discursivas sobre y en la empresa contemporánea se vale también de "la eliminación de las huellas de la degradación y los problemas en los campos de la calidad, la protección y la seguridad" $^{\prime 19}$. Ello se consigue básicamente deshaciéndose, privándoles de responsabilidades, apartándoles de zonas relevantes o directamente despidiéndoles,

\footnotetext{
${ }^{18}$ Dejours concede gran importancia en este aspecto a la presencia generalizada de los criterios de «calidad total» como condición necesaria de la certificación comercial. La satisfacción de las pautas de calidad requiere omitir elementos imprescindibles de la experiencia real del desempeño laboral ordinario, y en ese sentido se califica como una "llamada a la mentira", ya que da lugar a la obligación de defraudar, disimulando las dificultades e imperfecciones, e incumpliendo las normas del oficio (mintiendo así, por tanto, acerca del propio trabajo). Por ello, en realidad no sería más que un mero eslogan que se basa en una concepción falsa del trabajo. (Dejours, 2009a:81, 199-200; 2009b:12-13; 2010:40-43; 2009c:66-67).
}

${ }^{19}$ Los ejemplos al respecto aportados por Dejours son más que ilustrativos (2009a:91). 
de antiguos empleados que atesoran cierta experiencia laboral del pasado producto de su veteranía.

Por supuesto, los dos últimos procedimientos de "distorsión de la comunicación" (expresión de clara inspiración habermasiana) mencionados no están únicamente dirigidos al interior de la empresa (para evitar una eventual crisis de funcionamiento fruto del debate, en el seno de la misma, en torno al sufrimiento y lo real en el trabajo), sino que también —como indicábamos- están pensados para salvaguardar su imagen pública:

Lo que temen las empresas son los procesos judiciales y la posibilidad de que den lugar a debates públicos. Pero si previamente se han borrado las huellas, van a faltar las pruebas necesarias para la instrucción de la causa y la posterior inculpación (...) Y así se logra el objetivo de mantener el silencio y la estabilidad de la mentira. (Dejours, 2009a:92)

Por lo demás, la realidad del sufrimiento laboral ordinario es eclipsada por un sistema de prácticas discursivas que prolifera mediante diversos medios de «comunicación» interna cuyo discurso -diseñado por especialistas en comunicación que emplean técnicas importadas de la publicidad comercial masiva - posee dos características esenciales: a) siempre se muestra favorable a las reformas y reestructuraciones periódicas y los modos de organización concretos de que se trate; b) aparece plagado de imágenes, eufemismos, eslóganes, estereotipos y frases hechas varias que sirven a dicho propósito. Hay que resaltar que el éxito de este procedimiento supone la acción deliberada y coordinada de un buen número de personas que participan en la elaboración de documentos, así como la complicidad de los trabajadores entrevistados.

¿Por qué los mandos intermedios consienten y participan - personalmente y a sabiendas - de la mentira? Decíamos más arriba que la precarización del empleo aboca en última instancia a un solipsismo que explica el silencio y el habitual secreto de los propios asalariados sobre las dificultades experimentadas su actividad laboral y las fallas de la organización prescita. Pero, aunque a la base del consentimiento masivo de la mentira se encuentra sin duda el miedo ante la amenaza de despido, en el caso de los mandos intermedios se produce también, según Dejours, para hacer frente a lo que denomina «sufrimiento ético»: la mentira es racionalizada justificándose no a modo de fin en sí mismo sino como una suerte requisito insoslayable si no se quiere sucumbir en la coyuntura de la lógica económica imperante (Dejours, 2009a:99, 125).

Así pues, el fenómeno de la llamada «estrategia de distorsión comunicativa», que incluye la construcción, difusión y racionalización de la mentira, jugaría un papel esencial en el proceso de banalización de la injusticia. Desde luego, es un elemento que determina en buena medida que la sociedad civil no reciba información directa sobre lo que cotidianamente sucede en los lugares de trabajo. 


\section{ACEPTACIÓN DEL «TRABAJO SUCIO» Y ESTRATEGIAS COLECTIVAS DE DEFENSA.}

Además de los mecanismos de defensa clásicos descritos por el psicoanálisis, nuestro autor contempla también la existencia de estrategias colectivas de defensa desarrolladas por determinados grupos de trabajadores, algunas de las más importantes entran en escena en tanto que se ven impelidos a realizar periódica $u$ ordinariamente actos éticamente reprobables o cuando menos cuestionables. Estas estrategias contribuyen a salvaguardar el equilibrio mental en la medida en que combaten los efectos desestabilizantes y nocivos no sólo del «sufrimiento psíquico», sino también y fundamentalmente del ya aludido "sufrimiento ético», cuya forma por antonomasia es la mala conciencia. Las ideologías en cuestión corresponden sobre todo a quienes no se pueden "permitir el lujo» de mirar a otro lado mediante el recurso a las «anteojeras voluntarias», ya que son artífices directos de la injusticia: directivos y mandos intermedios que actúan en un contexto en el que conductas que en otro tiempo se consideraban una falta moral ahora se han convertido en norma. Nos referimos a acciones que necesariamente repercuten en gran número de víctimas: la violación sistemática de múltiples aspectos del derecho laboral, el constante empleo del chantaje, la amenaza y el engaño deliberado a los trabajadores, la explotación más descarada de los subordinados, el impago de horas trabajadas, el despido masivo, etc.

En la inmensa mayoría de los casos, la ejecución del trabajo sucio no es una tarea placentera, y únicamente puede ser asimilada y exhibida públicamente por los sujetos en tanto que se realiza en pro del trabajo, su calidad y su eficacia. De otra forma los agentes podrían aparecer como unos monstruos ante sí mismos. Pero, en cambio, cometidos en nombre del trabajo, esos actos pueden pasar incluso por «desinteresados» y - como veremos a continuación- en favor del interés de la nación, del bien público o cosas por el estilo. En cualquier caso, cuando este argumento se torna inviable, siempre cabe tratar de justificarse alegando: "ies mi trabajo!» «¡Es un trabajo como cualquier otro!», suponiendo tácitamente que todo cuanto se realiza en el marco del empleo y en función de la obligación laboral cobra en sí mismo, ya solamente por ello, un aura de licitud e irreprochabilidad casi incontestables (Dejours, 2009a:120-121) ${ }^{20}$.

Aunque si existe un relato ideológico que merece la mayor atención en este punto, es lo que en nuestro texto de referencia aparece bajo el rótulo de estrategia del cinismo viril. Ésta consiste, para decirlo rápidamente, en atribuir cierto carácter afeminado y, por ello, despreciable, a quien se niega a cometer el tipo de actos más arriba enumerados o experimenta cierta reticencia a llevarlos a cabo. Ello se basa, obviamente, en la suposición más o menos tácita y social e históricamente construida de que el grado de virilidad $^{21}$ de un individuo se mide ante todo en

\footnotetext{
${ }^{20}$ Suele apelarse en estos casos a lo que Hannah Arendt llamaba «teoría del engranaje», en cuanto síntoma de evasión de la propia responsabilidad. Vid. Bauman, 2011:191-192.

${ }^{21}$ Nuestro autor diferencia la «virilidad» de la «masculinidad». Asumiendo la distinción sexogénero, la primera queda definida como "las características del género social masculino" (Dejours, 2009a:118, cursiva mía).
} 
función de su capacidad para ejercer violencia sobre sus dominados ( $y$, como es bien sabido, no ser reconocido por el resto de varones como un auténtico hombre, en muchas ocasiones puede constituir la mayor de las vergüenzas). ¿Pero acaso lo verdaderamente valiente no sería negarse en voz alta a actuar de tal forma, asumiendo con entereza las consecuencias en términos de perjuicio personal que ello pueda acarrear? Desde la ideología en cuestión, sin embargo, esto último tiende más bien a afectar al prestigio ente los iguales, interpretándose como un síntoma de debilidad, cobardía, bajeza y falta de solidaridad entre colegas (Dejours, 2009a:110$11,113,136)^{22}$.

Téngase en cuenta, por otro lado, que desde el momento en que entran en escena procesos psicológicos y sociales como los recién descritos, lo que está operando en los sujetos es mucho más que un mero interés económico egoísta, puesto que estamos ante algo que no deja de ser una dimensión ético-moral del comportamiento, en la medida en que lo que se juega es la dignidad de uno, interpretada en este caso a través de "una serie de resortes psicológicos y sexuales" (Dejours, 2009a:112-113, 115-119, 121, 135, 137-138, 142, 173-177).

Cuando, aun recurriendo a los valores ligados a la virilidad, persiste la culpa y los sujetos se ven incapaces de enorgullecerse de su conducta, se suele apelar a la idea de que, en el contexto de una guerra económica inexorable, ciertos sacrificios son un mal menor necesario por el bien del país - para salvarlo del naufragio económico, por ejemplo- o de la empresa ${ }^{23}$. Así, en íntima conexión con la estrategia del cinismo viril aparece un relato de justificación que también servía de pretexto para sustentar consciente y deliberadamente la mentira por parte de los mandos intermedios, a saber, la ideología del realismo económico, gracias a la cual el cinismo puede hacerse pasar por fuerza de carácter y un alto sentido de la responsabilidad colectiva. Según el dispositivo ideológico en cuestión, la adopción de este punto de vista requiere, hasta cierto punto, de la presencia de virtudes muy próximas a las asociadas a la virilidad: coraje, audacia, arrojo, determinación, no huida de la realidad, etc. Mas lo fundamental es que, para evitar verse a sí mismos como «malas personas», las élites de la empresa se refugian, mediante un ejercicio de mala fe y evasión de la responsabilidad donde los haya, en el presunto carácter inevitable de la injusticia de la que son tanto cómplices como agentes directos, ya que ésta formaría parte del curso «natural de las cosas» entendido como «la evolución histórica de la economía». Cualquier negativa a oponerse a colaborar y participar de la dinámica sistémica a la que nos referimos constituiría, según esto, un

${ }^{22}$ Cf. Bauman, 2011:185-186.

${ }^{23}$ He aquí un ejemplo ilustrativo del importante papel de los valores bélicos y asociados a la virilidad en la retórica de legitimación del capitalismo neoliberal (este elemento aparece subrayado en la película Le Capital, a cargo del director Costa-Gavras, basada en la novela homónima escrita por Estephane Omont y publicada en 2004). Todo ello sugiere, por lo demás, una interesante conexión de nuestra temática con el ámbito de los estudios de género (sobre la relación de las mujeres con esta noción de virilidad en el ámbito laboral, vid. Dejours, 2009a:113, 138-139, 173, 174). 
gesto totalmente inútil, pueril y absurdo. Cualquier intento de resistirse implicaría simplemente una cierta incapacidad para asumir la realidad «tal cual es», en tanto que significaría oponerse obstinadamente ni más ni menos que a las leyes «científicas» de la economía. En definitiva, bajo esta justificación los sujetos se interpretan a sí mismos y a sus obligaciones rutinarias como parte de un juego al que es imposible no jugar, habida cuenta de la supuesta ausencia total de alternativas viables. La idea es muy clara: si uno quiere prosperar - una empresa, un Estado o un individuo- tiene que competir. No hay posibilidad alguna de sustraerse al juego de la competencia, so pena de sucumbir. Y sobrevivir y adelantar posiciones requiere realizar ciertos sacrificios.

Ello recuerda a muchos de los fenómenos de los que Richard Sennet se ocupa en un ensayo de máximo interés para nuestra temática, como es La corrosión del carácter. Allí se sostiene que bajo la ficción del trabajo cooperativo y de la responsabilidad colectiva que se da en el contexto de la organización laboral posfordista, se produce la ilusión ideológica de que directivos y trabajadores están todos en el mismo barco, del que se entiende que es legítimo tirar por la borda a los individuos sobrantes que - por una razón u otra- se han convertido en un lastre. En la estructura reticular del poder flexible, en contraste con la gran pirámide jerárquica y centralizada que constituía la forma característica del modo de producción industrial, nadie se responsabiliza de los actos de exclusión de las personas superfluas. Al concebirse ahora como «team leader», un mero guía o coordinador del pequeño grupo de trabajo, el jefe no se ve en absoluto obligado a asumir la responsabilidad de sus actos, lo cual viene a ilustrarse a la perfección mediante la declaración - que Sennet traía a colación- realizada por un directivo de ATT a propósito de un reciente aluvión de reducciones de plantilla: «la gente necesita reconocer que todos somos trabajadores contingentes de una forma u otra...», afirmaba el que es calificado por el sociólogo estadounidense como la figura más astuta de las que aparecen en las páginas de su libro, precisamente por "haber dominado el arte de ejercer el poder sin tener que presentarse como responsable" (Sennet, 2005:58, 120-121).

$\mathrm{Ni}$ que decir tiene que, normalmente, quienes tienden a abrazar sin reservas ese tipo de argumentarios son aquellos que, en el fondo, se creen protegidos del riesgo de hallarse, en algún momento, en la lista de los excluidos. En efecto, la realpolitik siempre resulta más fácil de tolerar para aquellos que no esperan caer víctimas de ella...

Es preciso advertir, por otro lado, hasta qué punto este fundamentalismo economicista se apoya en el importante papel de la creencia en la ciencia en el imaginario colectivo, elemento que favorece sobremanera la racionalización de los actos más arriba referidos. Efectivamente, desde la ideología en cuestión, rechazar la vigente realidad económica y laboral sería un síntoma inequívoco de una suerte de moralismo e idealismo recalcitrantes que sencillamente se niegan a aceptar el hecho de que las leyes económicas se encuentran más allá del bien y del mal. Estaríamos, pues, ante una especie de pretendido triunfo de la inteligencia sobre un cierto voluntarismo pueril que se niega a aceptar los límites impuestos por la naturaleza de las cosas. En una palabra: la referencia a la «ciencia» de la economía no deja lugar 
para debate político o moral alguno. Desde esta óptica, "oponerse al orden económico sería no sólo una tontería sino también una señal de oscurantismo", de manera que "la colaboración en el "trabajo" sucio puede conferir a los colaboradores el estatus de ciudadanos ilustrados" (Dejours, 2009a, 128-129).

\section{CONSIDERACIONES FINALES}

Si bien el texto posee un claro fondo u orientación normativa, lo recién expuesto está concebido, antes que nada, bajo una voluntad fundamental de comprensión. Vivimos en una coyuntura político-económica que ha dado lugar a un constante aumento de los índices de desigualdad social, a una creciente precarización del empleo, a un progresivo cuestionamiento del derecho laboral y del resto de estructuras del estado social, a una tendencial exclusión y desamparo de una parte de la población en pro del «buen funcionamiento» de la economía, etc. En semejante circunstancia social, en la que casi nadie está completamente a salvo de llegar a convertirse en un paria, la experiencia del miedo frente a los riesgos de precarización y de exclusión social adquiere gran protagonismo. Las páginas precedentes constituyen, en primer lugar, una tentativa de mostrar en qué sentido este fenómeno generalizado, sin embargo, bajo el supuesto tácito de la ausencia de alternativas y el darwinismo social más o menos explícitamente asociado a él, no genera precisamente oposición a las estructuras del sistema, sino que, muy al contrario, tiende a alentar un escenario de competitividad individualista sin el cual éstas no podrían sobrevivir (más aún, diríamos que es su motor mismo). Individualismo, competitividad entre trabajadores y declive de la lucha colectiva y de la conciencia del antagonismo de clase que, desde ámbito laboral, se ven impulsadas también por una serie de factores que, aunque en este trabajo no hayan sido propiamente tematizados, no dejan de resultar cruciales por cuanto están estrechamente vinculados a las transformaciones en los métodos de organización y dirección de empresas acaecidas progresivamente a partir de 1980 en el mundo occidental. No podemos dejar de mencionar aquí la implementación de procedimientos de evaluación individualizada y continua del rendimiento laboral (Dejours, 2009a:197-199; 2010:36-38; 2009b:12; 2009c:65-66; López Álvarez, 2016:687), el carácter efímero de la mayor parte de los contratos de trabajo, las prácticas habituales de reducción de efectivos o «limpieza de personal» (Dejours, 2009c:61-62), así como la estructura fragmentaria, reticular y «flexible» de la empresa postfordista y las particulares dinámicas de poder y control generadas en su seno (Sennet, 2005:10, 48-58, 115-123; Dejours, 2009b:81-83).

Por otra parte, conviene advertir que el tipo de trabajo remunerado que hemos contemplado no es su única modulación posible en nuestras sociedades. Si bien en esta ocasión hemos tomado como centro de gravedad de nuestro análisis la situación del trabajador asalariado bajo la organización empresarial contemporánea, ello no debería eclipsar el fenómeno de la crisis de la sociedad salarial (Moruno, 2015:24) y la vigente relevancia social de la emergente figura del trabajador por cuenta propia, otro fenómeno específico de nuestro tiempo que parece haber llegado para quedarse y a propósito del cual habría asimismo mucho que decir (López Álvarez, 2016). 
Tampoco hemos pretendido aportar ni mucho menos un catálogo exhaustivo de las distintas formas posibles de sufrimiento laboral en la actualidad, sino solo de algunas de aquellas que, según las investigaciones de nuestro psicopatólogo del trabajo, facilitan la asunción colectiva de ciertos constructos ideológicos particularmente relevantes en el discurso y el ethos neoliberal. Entretanto, esperamos haber sugerido la necesidad de sacar a la luz pública la realidad de la violencia ${ }^{24}$ de las relaciones laborales y, más en general, la pertinencia de prestar atención a la manera en que los seres humanos son tratados realmente por los nuevos métodos de organización y gestión del trabajo, en el marco de los cuales el sufrimiento no se ve necesariamente atenuado sino más bien incrementado y banalizado. Acaso dirigir la mirada hacia las consecuencias psicológicas y sociales del referido sistema de organización, gestión y dirección de empresas es un gesto del que no puede prescindir la teoría crítica de la sociedad en las actuales circunstancias.

Quizá no esté de más dejar claro que con todo ello no quisiéramos transmitir la idea de que el trabajo sea indiscutiblemente nocivo para quien lo ejerce, en el sentido de que acarreé por definición enfermedad e infelicidad ${ }^{25}$. El trabajo también puede ser, por diversas razones, fuente de realización personal. Ahora bien: datos como el constatable aumento de los casos de suicidio en el trabajo ${ }^{26}$ (iniciado en los países occidentales a lo largo de la década de los noventa), el hecho de que la salud mental en relación con el trabajo se deteriore cada vez más, el incremento efectivo de las patologías tanto psíquicas como somáticas ligadas a la sobrecarga de trabajo (Dejours, 2009a:200 ${ }^{27}$ ), así como el registro del recurso masivo a las aludidas estrategias psicológicas para salvaguardar el eventual desequilibrio psíquico como resultado del sufrimiento laboral generalizado, deberían bastar para darnos que pensar.

Lo anterior nos sitúa ante un importante supuesto subyacente al planteamiento adoptado, a saber: que es pertinente, e incluso esencial, atender al fenómeno del sufrimiento de los individuos para emprender la crítica social, pese a las innegables dificultades epistemológicas que ello comporta (Dejours, 2009a:43 [nota]). En efecto, la razón de ser de las estrategias psicológicas estudiadas no sería otra que la defensa contra el sufrimiento, y sólo por mor de su perpetuación, articulación y adopción masiva se hace posible la banalización de la injusticia tal y como ha sido entendida.

\footnotetext{
${ }^{24}$ Empleamos aquí el término violencia en sentido lato. Para un tratamiento de la cuestión específica de la violencia en sentido estricto en relación con la reconfiguración del mundo del trabajo asociada al Ilamado giro neoliberal, véase Dejours (2009c), donde se analiza el vínculo de esta última con el fenómeno de la violencia en el trabajo y de la violencia social creciente en nuestras sociedades.

25 "El trabajo no es neutral respecto a la infelicidad y la salud mental" (Dejours, 2010:26-34; 2009c:20-27; 2009a:31-32 [nota], 49, 133-134, 186; 2009b:55-70, 93-96).

${ }^{26} \mathrm{Al}$ análisis de este fenómeno está consagrado precisamente Trabajo y suicidio (Dejours, 2010); vid. Dejours, 2009a: 62-63, 195, 201; 2009b:10-11; 2009c:58-60.

${ }^{27}$ Zamora, 2013:166-168; Dejours, 2009b:205-215; Frayne, 2017:61-77.
} 
Valga reiterar, pues, que el interés de lo recién expuesto trasciende el ámbito de la sociología del trabajo y la temática del sufrimiento en el marco concreto del sistema contemporáneo de dirección de empresas, toda vez que las estructuras de organización del trabajo repercuten más allá del ámbito laboral como tal ${ }^{28}$. En este sentido, convendría tomarse muy en serio la tesis según la cual "las nuevas formas de organización del trabajo de las que se alimentan los sistemas de gobierno neoliberal tienen efectos devastadores sobre nuestra sociedad" (Dejours, 2009a:203), lo cual obliga a considerar determinados asuntos relativos a la organización del trabajo como cuestiones netamente políticas.

Baste lo dicho para, en definitiva, poner sobre la mesa la idea de que la toma de conciencia de la importancia del tema del sufrimiento en el trabajo y de algunas de las principales estrategias psicológicas defensa - a la postre ideológicas - como respuesta ante él, constituye un gesto indispensable para luchar contra eso que, con nuestro autor, podemos pensar en términos de banalización del mal en nuestras sociedades (Dejours, 2009a:140-164)29. Así, en la medida en que los aludidos procesos psíquicos defensivos complementarios se apoyan en relatos ideológicos como los que hemos contemplado (tornando así aceptable lo que no debería serlo), y teniendo en cuenta que "en materia de defensa contra el sufrimiento no hay leyes naturales, sino reglas de conducta construidas" por los seres humanos (Dejours, 2009a:27), el desmontaje teórico de aquellos se impone, sin duda, como una tarea esencial para un diagnóstico crítico del presente (Dejours, 2009a:169-170, 178).

\section{BIBLIOGRAFÍA}

BAUMAN, Zygmunt (2011): Modernidad y Holocausto, Madrid, Sequitur.

DEJOURS, Christophe (2009a) Trabajo y sufrimiento. Cuando la injusticia se hace banal, Madrid, Modus Laborandi.

—(2009b): El desgaste mental en el trabajo, Madrid, Modus Laborandi.

-(2009c): Trabajo y violencia, Madrid, Modus Laborandi.

-(2010): Trabajo y suicidio. Madrid, Modus Laborandi.

28 "Dada la importancia que damos al trabajo en nuestras vidas, decir organización del trabajo es decir qué clase de hombres forja la sociedad" (Dejours, 2009b:142).

${ }^{29}$ Por supuesto, se trata de una extrapolación (sugerente y provocadora donde las haya) de la célebre expresión popularizada en su día por Hannah Arendt a partir de su Eichmann en Jerusalén. En un trabajo posterior me encargaré del uso que Dejours hace de este concepto, así como de algunas sus importantes críticas de la manera cómo la pensadora alemana concibió el fenómeno en cuestión. 
EAGLETON, Terry (1997): Ideología. Una introducción, Barcelona, Paidós, 1997.

FRAYNE, David (2017): El rechazo del trabajo. Teoría y práctica de la resistencia al trabajo, Madrid, Akal.

HARVEY, David (2007): Breve historia de/ neoliberalismo, Madrid, Akal.

LAVAL, Christian/ DARDOT, Pierre (2013): La nueva razón del mundo: ensayo sobre la sociedad neoliberal, Barcelona, Gedisa.

LÓPEZ ÁlVAREZ, Pablo (2016): «La plasticidad forzada. Cuerpo y trabajo», en Daimon, Suplemento 5, pp. 680 y 688.

MORUNO, Jorge (2015): La fábrica del emprendedor. Trabajo y política en la empresa- mundo, Madrid, Akal, 2015.

NOGUERA, Antonio (2002): "El concepto de trabajo y la teoría social crítica», en Papers 68, 2002, 141-168.

— «El problema de la definición del trabajo» (Recurso online: https:/gsadi.uab.cat/images/pdfs/noguera/El\%20problema\%20de\%20la\%20definici\% C3\%B3n\%20del\%20trabajo.pdf)

RAVENTÓS, Daniel (1999): El derecho a la existencia, Barcelona, Ariel, 1999.

RENAULT, Emmanuel. "El sufrimiento social. Entrevista a Emmanuel Renault" (recurso online: http://espaienblanc.net/?autores=espai-en-blanc [última visita: 17-012019]).

SENNET, Richard (2005): La corrosión del carácter. Las consecuencias personales del trabajo en el nuevo capitalismo, Barcelona, Anagrama.

ZAMORA, José Antonio (2013): «Subjetivación del trabajo: dominación capitalista y sufrimiento», en Constelaciones-Revista de teoría crítica (no 5, pp. 166-168). 